\title{
An Optimality Theoretic Account of Place and Voice Assimilation in Bushehri Dialects
}

\author{
Aliyeh Kord-e Zafaranlu Kambuziya ${ }^{1 *}$, Pegah Aryaei $^{2}$, Sahar Bahrami Khorshid $^{3}$ \\ ${ }^{1}$ Associate Professor of General Linguistics, Tarbiat Modares University, Tehran, Iran. \\ Email: akord@modares.ac.ir \\ ${ }^{2}$ Graduate student in General linguistics, Tarbiat Modares University,Tehran, Iran. \\ email: pegah.aryaee@gmail.com \\ ${ }^{3}$ Assistant Professor of Linguistics, Tarbiat Modares University, Tehran, Iran. \\ email: sahbahrami@modares.ac.ir
}

\begin{abstract}
This paper intends to illustrate an analysis about one of the Common Phonological Processes in some regional varieties of Bushehri: assimilation, in the framework of Optimality Theory (McCarthy 2008). Bushehr Province with an area of 23167 square kilometers is located in south Iran. Speakers in this province can be divided in two general branches: northern and southern branches. Speakers in northern branch speak a dialect like Luri. Speakers in southern branch speak dialects that are like what is common in Fars Province. One of the taxonomy of assimilation is related to the influence of the sound features on the process of assimilation. This type of classification of assimilation can be according to two major parameters, place and voice. In Bushehri dialects there is a place assimilation in acuteness and graveness features. Hyman (1975:31) argues that both consonants and vowels differ in this acoustic property of graveness/ acuteness. In Bushehri variteis, the back round vowel [u] before [+acute] consonants changes to front unround vowel [i] that has [+acute] feature. Also in Bushehri dialects when voicless palatal [c] placed before a voiced consonant, or when voicless alveolar [s] placed before a voiced consonant, they take voice feature from the voiced consonant and change to their adjacent pair [z] and $[\mathrm{f}]$. Assimilation between adjacent segments is driven by the family of agreement constraints: AGREE [F]. Ranking AGREE $[x]$ above IDENT[x] guarantees assimilation, in the other word the final ranking is as follow: AGREE $[x]>>$ IDENT $[\mathrm{X}]$.
\end{abstract}

\section{KEYWORDS}

Optimality Theory(OT); assimilation; acute; grave; Bushehr; dialect.

\section{INTRODUCTION}

The purpose of the present study is to provide an overview aboat one of the common phonological processes in Bushehri dialects: assimilation, and to review the theoretical implications of this process. Bushehr province is located in south Iran. Northward, it is bounded to Khuzestan and Kohkiluye-Boyer-Ahmad, Eastward to Fars Province, Southward and Westward to the Persian Gulf. Bushehr have 10 counties.

Speakers in this province can be divided in two general branches: northern branch that involve Dashtestan, Genaveh, Daylam, Bushehr and some parts of Tangestan county and southern that involve some parts of Bushehr, Dayyer, Jam, Kangan and Tangestan. Speakers in northern branch speak a dialect like Luri. Speakers in southern branch speak dialects that are like what is common in Fars Province.

Windfuhr (2009:418) said that: In SW Iran there is two groups which can be recognized as "Perside", i.e. they continue numerous features that evolved from Southern Early New Persian, though each evolved differently:

(1) The Luri-type dialects (Luri proper, Bakhtiari, Boyer-Ahmadi, Mamasani-Kohkiluye).

(2) The Fars dialects stretching from the Persian Gulf into western and central part of Fars.

\subsection{The Consonant and vowel System of Bushehri dialects}

Before the representation of the data, it seems necessary to represent consonants and vowels tables of Bushehri dialects. The phonological system of Bushehri dialects consists of 24 consonants and 7 vowels. The consonantal inventory of Bushehri dialects can be classified as follows: eight stops ( $p, b, t, d, c, J, q, ?)$; nine fricatives ( $f, v, s, z, \int, z, x$, $\mathrm{Y}, \mathrm{h}$ ); two affricate (dz, $\mathrm{t} f)$; two nasals $(\mathrm{m}, \mathrm{n})$; one lateral $(\mathrm{l})$; one trill $(\mathrm{r})$ and one glide (j). The difference between phonological system of standard Farsi and Bushehri dialects is that, instead of the voiced uvular consonant /G/ in standard Farsi, there is voiceless uvular consonant $/ q /$ in Bushehri dialects. Also in Bushehri dialects there is consonant $/ \mathrm{y} /$ that Farsi lacks it. In Bushehri 's phonetic system like Farsi , there are two palatal plosives /c/ and / f /, but before back vowels they are pronounced [k] and [g], respectively; such as [kur] "blind", [?angur] "grips". So [k] and [g] are allophones of /c/ and $/ \mathrm{J} /$ that make no meaning distinction.

Among the simpler vowel systems in the languages of the world is the standard Farsi vowel system. It is composed of six vowels. Six vowels are generally recognized: three front vowels /i/, /e/ and /a/ and three back vowels /u/, /o/ and /a/. Bushehri dialects vowel system just alike Farsi. In Bushehri dialects, in addition to six vowels of standard Farsi, there is a vowel / ə /. Table (1) illustrates the vowel system in Bushehri dialects. 
Table1. Vowel distinctive features of Bushehri dialects

\begin{tabular}{|c|c|c|c|c|c|c|c|}
\hline & $\mathrm{a}$ & $\mathrm{a}$ & $\mathrm{e}$ & $\mathrm{o}$ & $\mathrm{i}$ & $\mathrm{u}$ & ə \\
\hline back & - & + & - & + & - & + & - \\
\hline high & - & - & - & - & + & + & - \\
\hline low & + & + & - & - & - & - & - \\
\hline tense & - & + & + & + & + & + & - \\
\hline round & - & + & - & + & - & + & - \\
\hline
\end{tabular}

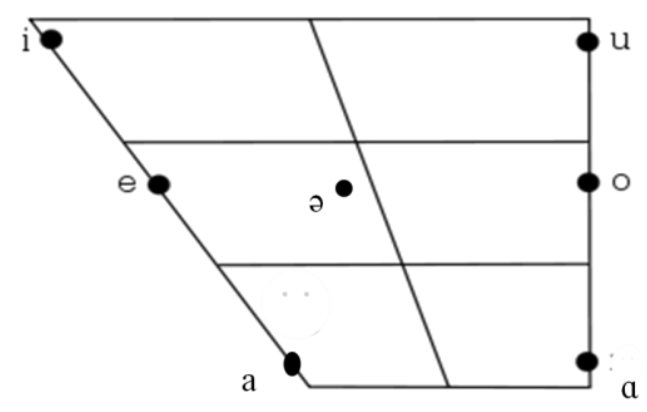

Fig1: Bushehri dialects vowels diagram

\subsection{Syllable Structure}

The Bushehri dialects syllable may have three components: a peak, an onset and a coda. The nature of these components is as follow: "the peak, or nucleus, is always the most prominent element of the syllable. It must be composed of a vowel, either long or short. The marginal elements, on the other hand, contain only consonants, the onset always consisting of a single consonant and the coda consisting of zero, one, or two consonants."

Put differently, the following formula can be utilized to describe the syllable structure in Bushehri: $\mathrm{C}_{1} \mathrm{VC}_{0}-2$.

a.CV: as in the word: /ko/ "mountain"

b.CVC: as in the word: /dim/ "tail"

c. CVCC: as in the word of /vaxt/ "time"

\section{THEORETICAL FRAMEWORK}

The theoretical framework used in this study, namely Optimality Theory (OT), came into existence in early 1990s, mainly focusing on contemporary phonological studies (Prince and Smolensky, 1993; McCarthy and Prince, 1999; Mac Carthy, 2001). This theory was developed as a response to a "conceptual crisis at the center of phonological thought" (Prince and Smolensky, 1993) concerning the role of output constraints. It was also inspired by the concepts of neural networks, as shown by the significance of ideas such as optimization, parallel evaluation, competition, and conflicting constraints which are also present in the framework of OT. Optimality Theory is often considered as a development of generative grammar and the successor of the harmonic grammar developed in 1990s (Legendre et al., 1990, 2001; Prince and Smolensky, 1993; Smolensky and Legendre, 2006, a.o.). In a typical OT analysis, the phonological constraints are ranked and violable by the phonetic forms of their underlying Representations in a tableau. This is a constraint-based competition system among a possibly infinite set of candidates (at least two) that are actually the potential surface forms of the input. The candidates minimally violate the constraints and the one that incurs the least serious violations in terms of hierarchies of constraints, wins. Hence, logically, the violations of higher-ranked constraints are most serious and these violations first oust the concerned candidate from the competition and so on. An OT-style tableau, which uses harmony maximization as the criterion for optimality where the weights are in the top row and the rightmost column, provides the harmony values for the candidates (Kar, 2009). This framework can effectively analyze various aspects of phonological issues in a language in a comprehensive and systematic manner.An outline of the "classic" OT looks like as follow:

Input $\rightarrow$ GEN $\rightarrow$ candidate set $\rightarrow$ EVAL (constraints) $\rightarrow$ Optimal Output

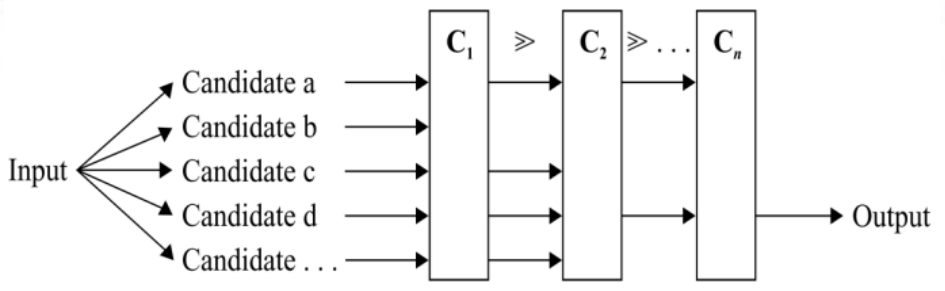

Fig 2. Mapping of input to output in OT (kager, 2004:8)

\section{METHODOLOGY}

The method of this research is analytical- descriptive. In order to conduct the study, ten native speakers, selected from different age groups (from 20 to 60 year-old ones) and different educational levels were interviewed. The corpus primarily contains free conversation and life stories.

Here, McCarthy's (2008) combination tableau was adapted The combination tableau illustrates the ranking between constraints, as well as violation marks. In the tableau, each losing $(\mathrm{L})$ candidate is compared to the winning $(\mathrm{W})$ candidate in regards to each constraint. (W) Denotes that the constraint in question prefers the winner rather than the losing 
candidate. This is why the winner satisfies the constraint but the losing candidate does not, as specified by the violation mark $\left(^{*}\right)$.Whereas the $(L)$ denotes that the given constraint prefers the losing candidate rather than the winner $(\mathrm{W})$.

\section{Discussion}

\subsection{Assimilation}

Bakovic (2007:335) assumes that the process of assimilation can be generally partitioned into two major types, local and long-distance. The cases of local assimilation take place rigorously between adjacent segments, such as between consonant segments within a consonant cluster. On the other hand long-distance assimilations occur between segments, whether consonants or vowels which are not adjacent such as consonants across a vowel.

Crystal (2008:40) illustrates that several classifications of assimilation can be found. One of the classifications is due to whether the segment shifting is the consequence of the effect of a neighboring sound or of one that is not adjacent. The first type which is local assimilation is the common one. Crystal calls it contiguous or contact assimilation, and calls the other type non-contiguous or distance Assimilation. Lass (1984:171) give an example of long distance assimilation in which the sound $/ \mathrm{n} /$ changes into $/ \mathrm{m} /$ : open/ əupuən / $\rightarrow$ open /əupəm/. Here, the sound /n/ is changed into the $/ \mathrm{m} /$ because of the influence of the sound $/ \mathrm{p} /$.

Crystal (2008:40) gives an example for long distance assimilation in which again the sound $/ \mathrm{n} / \mathrm{changes}$ into $/ \mathrm{m} /:$ turn up

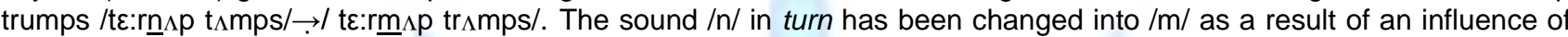
$/ \mathrm{p} /$ in up. He further argues that long distance assimilation occurs in languages having vowel harmony, in which a vowel in one part of a word may influence other vowels to be articulated similarly, despite the fact that there are other sounds separating the assimilated vowels.

There is another form of categorizing assimilation according to the direction of assimilation. Carr (1999:16) states that in regressive assimilation the first of two sounds undergoes assimilation to a coming sound. He also considers this type as the most common type of assimilation. According to Trask (1996: 26) regressive assimilation is a phenomenon in which a phonetic attribute extends to a preceding segment, which he also calls anticipatory co-articulation. Crystal (2008: 40) argues that there are three possibilities in what concerns the direction of assimilation. To him, the first one is regressive or anticipatory as explained above, the second type is progressive assimilation in which a sound changes as a result of the effect of the preceding sound. The occurrence of this type of assimilation in English is very few and it is not common. The third type is coalescent or reciprocal' assimilation in which there is a shared effect or mixture of the sounds on one another. For example: ten bikes /ten barks $/ \rightarrow$ tem barks/.

The direction of assimilation here is from left to right (regressive or anticipatory assimilation) in which the sound /n/ in ten has been assimilated to the sound $/ \mathrm{m} /$ as a result of the influence of the $/ \mathrm{b} /$ in the word bike.

Another taxonomy of assimilation is related to the influence of the sound features on the process of assimilation. Lass $(1984: 173)$ states that the process of assimilation greatly influences almost all the sound segments. The above classifications of assimilation can be according to two major parameters, place and voice. In place assimilation the assimilating segment spreads the feature of place onto the assimilated sound. If the assimilating segment is bi-labial, as a result of the assimilation process the assimilated sound will copy the place feature bi-labial from the assimilating segment as: ten bikes /ten barks $/ \rightarrow /$ tem barks/.

Here the sound $/ \mathrm{n} /$ in ten is an alveolar sound, while the sound /b/ in bike is bi-labial, that is why the sound /n/ has been assimilated to a bi-labial sound which is $/ \mathrm{m} /$.

The other type is voice assimilation, Carr (1999: 16) explains that voice assimilation is a common kind of the process in which the assimilated segment takes voice feature from the assimilating sound. Katamba (1989:81) explains that the plural marker "s" in English is a fine example of voice assimilation; for instance: pet /pet / $\rightarrow$ pets /pets /, bed /bed / $\rightarrow$ beds /bedz /.

The last point about the classification of assimilation will be about whether the assimilated sounds are totally assimilated or partially. Crystal exemplifies the case by stating that in an instance like: ten bikes, /ten barks $/ \rightarrow$ [tem barks].

The sound $/ \mathrm{n} /$ is assimilated to the sound /b/ only in the place feature not in both features of place and voice that is why the assimilation is partial not total. But in the example: ten mice,

/ten mals/ $\rightarrow$ [temmals].

The sound $/ \mathrm{n} /$ in the word ten is changed to the sound [m]. Here the assimilated sound is totally similar to the assimilating sound that is why the assimilation is total.

\subsubsection{Place assimilation (acutness and graveness features)}

Hyman (1975:31) argues that: "since the earliest phonetic studies, segments have been classifiied according to their articulatory properties. In consonants, for example one asks where a sound is made (place of articulation), how it is made (manner of articulation), and what the state of glottis is (voiced, unvoiced, ect.). in vowel, one asks which part of the tongue is raised (front, back, central), how much it is raised (high, mid, low), and whether the lips are rounded. While this is the most common and oldest way of classifying sounds, it is now possible with technological advances to group sounds according to their acoustic properties. That is phonetic features such as the one distinguishing [p] from [b] can be stated 
either in terms of what is involved in the production of such sounds in the vocal tract or in terms of the characteristics of the acoustic sign which results from the different articulatory gestures. In other words, segment can be similar (or dissimilar) either in the way they are made or in the way they sound two aspect which are related."

A number of phonological properties cannot be accounted without considering the acoustic properties of the sounds in qustion. A simple case is seen in the following data from some varietis of Bushehri such as Deylami, Dashtestani, Liravi and Shuli:

Table 2. Assimilation in acuteness feature (a)

\begin{tabular}{|c|c|c|c|c|}
\hline Bushehri & Standard persian meaning & Bushehri & dard pel & meaning \\
\hline \multicolumn{2}{|c|}{ before palatal consonants } & \multicolumn{3}{|c|}{ before alveolar consonants } \\
\hline ri & face & xin & Xun & blood \\
\hline pic & hollow & Savin & sabun & soap \\
\hline \multicolumn{2}{|c|}{ before dental consonants } & terazin & tarazu & scale \\
\hline tit & berry & pine/ pidom & pune & pennyroyal \\
\hline fit & puff & tanir/ tenir & tanur & furnace \\
\hline belit & chestnut & dir & dur & far away \\
\hline $\mathrm{zi}$ & very soon & pil & pul & money \\
\hline $\mathrm{dið} / \mathrm{di}$ & smoke & tile & tule & whelp \\
\hline bið & bud & ciza/ cize & cuze & jug \\
\hline riðu & bowel & heni & hanuz & still, yet \\
\hline \multicolumn{2}{|c|}{ before alveo-palatal consonants } & sizan & suzan & needle \\
\hline ci. tfa/ ci. tfe & cutfe & pisiðe & puside & rot, ruined \\
\hline dzidze & chicken & & & \\
\hline kolitfa & kolutfe & & & \\
\hline
\end{tabular}

As it can be seen in table (2), in these variteis, the back round vowel [u] before some consonants changes to front unround vowel [i]. In such words the difference between $[\mathrm{u}]$ and [i] is totaly redunant. Before consonants like $\{j, c, t, d, n, r$, $\mathrm{I}, \mathrm{z}, \mathrm{s}, \mathrm{d}, \mathrm{t}, \mathrm{t}\}$ the vowel [i] is applied, why?

While a front vowel might be accpected to be backed before a back (velar) consonant, the changes of [u] to [i] before mentioned consonants is not so easily explained. It would appear that these consonants, which function together in this fronting process, have some phonetic feature in common, and yet articulatorily they are made at the same extreme in the oral cavity.

The reason is that the consonants such as $\{\mathrm{j}, \mathrm{c}, \mathrm{t}, \mathrm{d}, \mathrm{n}, \mathrm{r}, \mathrm{I}, \mathrm{z}, \mathrm{s}, \mathrm{d}$, t $\mathrm{t}\}$ share an acoustic property which the other consonants like $\{b, p, m, x, y\}$ do not share. Since labial and velar consonants are made at the periferies of the oral cavity (two at the back of the mouth $\{x, y\}$, some at the labial $\{b, p, m\}$ ) produces a concentration of energy in the lower frequencies of the sound spectrum. Since alveolar/ dental and palatal sounds cut the oral cavity in two parts, they do not create a large oral cavity, but rather two smaller cavities. Consequently, they have in common a consentration of energy in the upper frequencies of the sound spectrum. This acoustic distinction is directly incorporated into the feature system proposed by Jakobson et al. Labial and velar consonants are said to share the property of graveness (low tonality) and alveolars and palatals (also palato- alveor and all coronals in case of Bushehri varities) share the property of acuteness (high tonality).

Back vowels like labial and velar consonants, are made at the periphery of the oral cavity, since the tongue is raised in the back of the mouth; front vowels, like dental/alveolar and palatal consonants, are made in non-peripheral (or medial) part of the oral cavity, since the tongue is raised in the center of the mouth. Consequently, both consonants and vowels differ in this acoustic property of graveness/ acuteness, as follows:

Gerave

Labial consonants

Velar consonants

Back vowels
Acute

Dental/alveolar consonants

Palatal consonants

Front vowels

The data in table (2) shows that a grave high vowel becomes an acute high vowel before an acute consonant. This formulation reveals that the process in question is phonetically motivated: back vowels change to agree in acuteness with the consonants after them. This phenomenon involve cases of assimilation by which segment acquires the feature(s) of 
surrounding segments. This kind of assimilation can be either articulatory or acoustic in nature, depending on the feature which is being assimilated.

It is assume that assimilation between adjacent segments is driven by the family of agreement constraints (Lombardi 1996ab, 1999; see also Beckman 1998, Butska 1998, Bakovic'2000) defined in (1):

(1) AGREE [F]: Adjacent segments must have the same value of the feature [F].

It is supposed that an agreement constraint is violated once for each transition from one value of the relevant feature to the other; thus, whether the concept 'feature value" in the preceding means binary plus'+' vs. minus '-' or presence vs. absence of a feature is absolutely irrelevant. An agreement constraint compares adjacent segments and assesses a violation if and only if they differ in terms of the feature in question. Assuming that the feature [acute] is binary, AGREE [acute] is violated by a [+acute] consonant adjacent to a [-acute] vowels, in either order, and is satisfied otherwise.

Consider the following simplified example.Take two adjacent output segments $x$ and $y$.If $x$ and $y$ have the same value of $[F]$, as in $(2 a, b)$, then AGREE [F] is satisfied. If $x$ and $y$ have different values of $[F]$ in the output, as in $(2 c, d)$, then AGREE [F] is violated (Bakovic', 2000: 6).

(2) Satisfy AGREE[F] Violate AGREE[F]
a. $x \quad y$
C. $x \quad y$
$[-\mathrm{F}][+\mathrm{F}]$
$[-\mathrm{F}] \quad[-\mathrm{F}]$
b. $x \quad y$
d. $x \quad y$
$[+\mathrm{F}] \quad[+\mathrm{F}]$
$[+\mathrm{F}][-\mathrm{F}]$

For analyzing the data in table (2) we use two constraints: One is the markedness constraint AGREE [acute] and the other is a faithfulness constraint IDENT [acute].

(3) AGREE [acute]: adjacent segments must share the same value for the feature [acute].

(4) IDENT [acute]: Correspondent segments must have the same value of the feature [acute].

According to Baković (2007:337) the need for ranking AGREE[x] above IDENT[x] for the sake of guaranteeing assimilation will be shown in a tableau. Tableau (6) explains the case in which an input that contains adjacent segments that disagree in their value of $x$, with an output in which those segments have been changed to agree in terms of $x$ that works better than input-faithful substitute in which no change has been made. The format of the tableau is based on the models used by (McCarthy 2008) to show the ranking of the constraints.

Tableau 1. The model used for showing assimilation

\begin{tabular}{|l|l|l|}
\hline$/+\mathrm{x}-\mathrm{x} / \rightarrow /+\mathrm{x}+\mathrm{x} /$ & AGREE $[\mathrm{x}]$ & IDENT $[\mathrm{x}]$ \\
\hline$/+\mathrm{x}+\mathrm{x} / \approx /+\mathrm{x}-\mathrm{x} /$ & Optimal (winner) & *Loser \\
\hline
\end{tabular}

Tableau 2 (i, ii, iii, IV) presents analyses of the inputs /sabun/, /tanur/, /xub/ and /tup/.

Tableau 2. Assimilation in acuteness feature

\begin{tabular}{|c|c|c|c|}
\hline \multicolumn{2}{|c|}{ i. /sabun/ } & \multirow{2}{*}{$\begin{array}{c}\text { AGREE } \\
\text { [acute] }\end{array}$} & \multirow{2}{*}{$\begin{array}{c}\text { IDENT } \\
\text { [acute] } \\
*\end{array}$} \\
\hline a. & $\rightarrow$ [savin] & & \\
\hline b. & [sabun] & $* \mathrm{~W}$ & $\mathrm{~L}$ \\
\hline & [sabon] & $* \mathrm{~W}$ & $\mathrm{~L}$ \\
\hline \multicolumn{4}{|c|}{ ii. /tanur/ } \\
\hline a. & $\rightarrow[$ tanir $]$ & & $*$ \\
\hline b. & [tanur] & $* \mathrm{~W}$ & $\mathrm{~L}$ \\
\hline & [tanor] & $* \mathrm{~W}$ & $\mathrm{~L}$ \\
\hline \multicolumn{4}{|c|}{ iii./xub/ } \\
\hline a. & [xib] & $* \mathrm{~W}$ & $* \mathrm{~W}$ \\
\hline & $\rightarrow[\mathrm{xub}]$ & & \\
\hline \multicolumn{4}{|c|}{ IV. /tup/ } \\
\hline a. & [tip] & $* \mathrm{~W}$ & $* \mathrm{~W}$ \\
\hline b. & $\rightarrow$ tup $]$ & & \\
\hline
\end{tabular}

Candidate (a) in Tableau (2.i) is the winner since it obeys AGREE [acute] by changing the front high vowel [u] to the back high vowel [i] which is agree with the consonant after it in feature [+acute]. This candidate has one violation of faithfull constraint IDENT[acute], since it changes this feature in output. Candidate (b) and (c) are losers, since they do not satisfy AGREE[acute], despite obeying IDENT[acute]. Finally Candidate (a) is the optimal candidate. Candidates in Tableau (2.ii) have the same situation, and winner is the candidate (a). But in Tableaux (2.iii \& 2.IV) the winner is not the candiate 
changing the vowel [u] to [i]. In Tableau (2.iii) the candidate (a) is a loser because the vowel and the consonsnt after it do not agree in feature acutness and also changing the vowel in input, caused this candidate violates the constraint IDENT[acute]. Consequently, candidate (a) violates two constraits and loses this competition. Condidate (b) satisfy both constraints and wins. In Tableau (2.IV) the situation is like Tableau (2.iii). A a result a direct ranking relationship is found between AGREE [acute] and IDENT [acute] as shown in Tableau 2. Markedness constraint AGREE [acute] dominates faithfulness constraint IDENT [acute]. This ranking of constraints explains why our data is the optimal and winner candidate. The ranking is as follow:

(5) AGREE [acute] >> IDENT [acute].

The data in the table (4) shows that a grave front vowel [a ] becomes an acute back vowel before an acute consonant [j].

Table 3. Assimilation in acuteness feature (b)

\begin{tabular}{|ccc|}
\hline Bushehri & Standard Persian & meaning \\
\hline heðejat & hedajat & guidance \\
rezejat & rezajat & satisfaction \\
dsenejat & dzenajat & felony \\
\hline
\end{tabular}

For presenting an analysis to the mentioned data, we can use the cinstraints AGREE[acute] and IDENT[acute]. Tableau (3) presents analysis of the word /hedajat/.

Tableau 3. Assimilation of vowel /a/ with palatal glide /j/

\begin{tabular}{|c|c|c|}
\hline /hedajat/ & AGREE[acute] & IDENT[acute] \\
\hline $\begin{array}{r}\text { a. [he.de.jat] } \\
\text { [+acute] }\end{array}$ & $*$ \\
\hline $\begin{array}{r}\text { b. [he.da.jat] } \\
\text { [-acute] [+acute] }\end{array}$ & $* \mathrm{~W}$ & $\mathrm{~L}$ \\
\hline
\end{tabular}

Tableau (3) demonstrates that AGREE[acute] is the high ranking costraint.The winning candidate (a) obeys AGREE [acute] at the expense of IDENT [acute] and IDENT [acute]. Vowel [e] and palatal [j] have the same value about acuteness. Candidate (b) is the loser since it does not satisfy AGREE [acute], despite obeying IDENT [acute].

\subsubsection{Voice Assimilation}

As we explained before, one type of assimilation is voice assimilation. In bushehri dialects like Dashtestani, Ddeilami,Gami,ect. When voicless palatal [c] placed before a voiced consonant, it takes voice feature from the voiced consonant. Table (4) shows this type of assimilation.

Table 4. Voice assimilation (a)

\begin{tabular}{|ccc|}
\hline Bushehri & Standard Persian & meaning \\
\hline neJ.vat & nec.bat & misery \\
taJ.lif & tac.lif & task \\
PaJ.var & ac.bar & major (a name) \\
Jij.re.la & foc.rol.lah & a name \\
Jijr & focr & gratitude \\
fiłr/feJr & fecr & thought \\
doJme & docmeh & bottom \\
faJme & facmeh & boot \\
doJdor & doctor & doctor \\
\hline
\end{tabular}

In analyzing the data in table (4) we can use of the family of agreement constraints AGREE [F].

(6) AGREE [voice]: adjacent segments must share the same value for the feature [voice].

(7) IDENT [voice]: correspondent segments must have the same value of the feature [voice]. 
Tableau 4. Voice assimilation (a)

\begin{tabular}{|c|c|c|}
\hline$/$ taclif/ & $\begin{array}{c}\text { AGREE } \\
\text { [voice] }\end{array}$ & $\begin{array}{c}\text { IDENT } \\
\text { [voice] }\end{array}$ \\
\hline a. $\rightarrow$ [tajlif] & & $*$ \\
\hline b. $[$ taclif] & $* \mathrm{~W}$ & $\mathrm{~L}$ \\
\hline
\end{tabular}

Candidate (a) in Tableau (4) is the winner because two adjacent consonants have the same value for [voice] and it obeys AGREE[acute]. This candidate has one violation of faithfull constraint IDENT[voice], since it changes this feature in output. Candidate (b) is a loser. It does not satisfy AGREE[voice], despite obeying IDENT[voice]. Finally Candidate (a) is the optimal candidate. The ranking for constraints is as follows:

(8) AGREE [voice] >> IDENT [voice]

The data in table (5) shows voice assimilation in Dashtestani. When voicless alveolar [s] placed before a voiced consonant, it takes voice feature from the voiced consonant and changes to its adjacent pair [z]. Table (5) shows this type of assimilation.

Table .5 voice assimilation (b)

\begin{tabular}{|ccc|}
\hline Bushehri & Standard Persian & meaning \\
\hline nezvat & nesbat & kinship \\
tazvi & tasbi & rosary \\
tazdiq & tasdiG & authentication \\
\hline
\end{tabular}

In analyzing the data in table (5) in addition to the constraints in the Tableau (3), we use another markedness and faithfullness constraint:

(9) *FricBilabiPlosive: No fricative plus bilabial plosive sequences.

(10) IDENT[cont]: correspondent segments must have the same value of the feature [continuant].

Tableau (3) present analysis of the word /tasbi/.

Tableau 5. Voice assimilation (b)

\begin{tabular}{|l|c|c|c|c|}
\hline$/$ tasbi/ & $\begin{array}{c}\text { AGREE } \\
\text { [voice] }\end{array}$ & $\begin{array}{c}\text { FricBilabi } \\
\text { Plosive }\end{array}$ & $\begin{array}{c}\text { IDENT } \\
\text { [voice] }\end{array}$ & $\begin{array}{c}\text { IDENT } \\
\text { [cont] }\end{array}$ \\
\hline a. $\rightarrow$ [tazvi] & & & $*$ & $*$ \\
\hline b. $[$ tasbi] & $* \mathrm{~W}$ & $* \mathrm{~W}$ & $\mathrm{~L}$ & $\mathrm{~L}$ \\
\hline c. $[$ tasvi] & $* \mathrm{~W}$ & & $\mathrm{~L}$ & $*$ \\
\hline d. $[$ tazbi] & & $* \mathrm{~W}$ & $*$ & $\mathrm{~L}$ \\
\hline
\end{tabular}

Candidate (a) in Tableau (4) is the winner. It obeys two high ranking markedness constraints AGREE[voice] and ${ }^{*}$ FricBilabiPlosive by changing the voicless alveolar [s] to adjacant voiced pair of itself [z]. Candidate (a) is optimal at the expense of violation from IDENT [voice] and IDENT [cont].

Candidates (b) and (c) violate the high ranking constraint and lose this competition. Candidate (d) despite satisfying the AGREE [voice], has violated *FricBilabiPlosive, because it has sequences of fricative plus bilabial plosive consonants. There is no confliction between AGREE [voice] and *FricBilabiPlosive. Consequently we cannot establish a direct ranking, hence the dashed lines placed between them. Since IDENT [voice] and IDENT [cont] do not conflict, the dashed lines placed between them too. Finally Candidate (a) is the optimal candidate and the ranking us as follows:

(11) AGREE[voice] ; *FricBilabiPlosive >> IDENT[voice]; IDENT[cont]

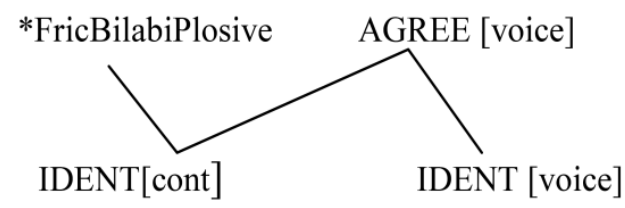

Figure.2 Hasse diagram for Tableau (5)

\section{CONCLUSION}

One of the taxonomy of assimilation is related to the influence of the sound features on the process of assimilation. This type of classification of assimilation can be according to two major parameters, place and voice. In Bushehri dialects there is a place assimilation in acuteness feature. Hyman (1975:31) argues that both consonants and vowels differ in this 
acoustic property of graveness/ acuteness as follows: grave (labial and velar consonants, back vowels) and acute (dental/ alveolar, Palatal consonants, Front vowels).

In Bushehri dialects, the back round vowel [u] before [+acute] consonants changes to front unround vowel [i]which has [+acute] feature. Also in Bushehri dialects When voicless palatal [c] placed before a voiced consonant, or when voicless alveolar [s] placed before a voiced consonant, they take voice feature from the voiced consonant and change to their adjacent pairs [z] and [f]. Assimilation between adjacent segments is driven by the family of agreement constraints: AGREE [F]. Ranking AGREE[x] above IDENT[x] guarantees assimilation, in the other word the final ranking is as follow: AGREE $[\mathrm{x}]$ >> IDENT [x]. Consequently, both consonants and vowels differ in this acoustic property of graveness/ acuteness, as follows: grave (labial and velar consonants, back vowels) and acute (dental/ alveolar, palatal consonants, front vowels)

\section{REFRENCES}

1) Bacovic, E., (2000). Harmony, Dominance and Control. Ph.D thesis, Rutgers University: New Brunswick, NJ. [ROA360].

2) Bakovic, E., (2000). Local Assimilation and Constraint Interaction. de Lacy (ed.), The Cambridge Handbook of Phonology, 335-352. Cambridge University Press.

3) Beckman, J., (1998). Positional Faithfulness, Positional Neutralisation and Shona Vowel Harmony. Phonology $14,1$. 46.

4) Carr, Ph., (1999). English Phonetics and Phonology; an introduction. Oxford: Blackwell.

5) Crystal, D., (2008). A Dictionary of Linguistics and Phonetics. Oxford: Blackwell.

6) Hyman, L., (1975). Phonology Theory and Analysis. New York: Holt, Rinehart \& Winston. Pp. xiii+268.

7) Hyman, L., (1985). A Theory of Phonological Weight. Dordrecht: Foris.

8) Kager, R., (2004). Optimality Theory. Cambridge: Cambridge University Press. $2^{\text {nd }}$ ed.

9) Kar, S., (2009). Gemination in Bangla: An Optimality-theoretic analysis. The Dhaka University Journal of Linguistics 1 (2), 87-114.

10) Katamba, F,. (1989). An Introduction to Phonology. Addison Wesley Longman Publishing, New York.

11) Lass, R. (1984). Phonology: an Introduction to Basic Concepts. Cambridge: Cambridge University Press.

12) Lombardi, L., (1996a). Positional Faithfulness and Voicing Assimilation in Optimality Theory. Ms., University of Maryland, College Park.

13) Lombardi, L., (1996b). Restrictions on direction of voicing assimilation: an OT account. University of Maryland Working Papers in Linguistics 4, 84-102. [ROA- 247.]

14) Lombardi, L., (1999). Positional Faithfulness and Voicing Assimilation in Optimality Theory. NLLT 17, $267-302$. Butska, Luba. 1998. Faithfulness to [voice] in Ukrainian: An Analysis of Voicing Alternations within Optimality Theory. In R. Artstein and M. Holler (eds.), RuLing Papers 1 (Working Papers from Rutgers University), 59-73.

15) McCarthy, J. (2008). Doing optimality theory: Applying theory to data. Malden, MA: Blackwell Publishing. doi: $10.1002 / 9781444301182$

16) Trask, R. L., (1996). Dictionary of Phonetics and Phonology Taylor \& Francis Routledge, London.

17) Windfuhr, G., (2009). The Iranian Languages. Routledge, Taylor \& Francis Group, London and New York.

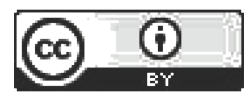

This work is licensed under a Creative Commons Attribution 4.0 International License.

DOI : 10.24297/jal.v6i3.4662 